\title{
A 10 Step Framework to Implement Integrated Care for Older Persons
}

\section{Patrick John Harnett ${ }^{1}$ (D) $\cdot$ Siobhan Kennelly ${ }^{2} \cdot$ Peter Williams $^{3}$}

Published online: 26 June 2019

(C) The Author(s) 2019, corrected publication 2019

\begin{abstract}
An aging population, whose multi-morbidities and risk of frailty increase with age results in significant health and social care consumption. Increasing complexity amplifies fragmentation of care and results in sub optimal care outcomes. Ireland, in keeping with other jurisdictions seeks to implement integrated care for older persons as a policy response. There is growing evidence base supporting effective service responses for older persons. These typically include multidisciplinary, community based teams providing services in or near to the older person's home (the 'what'). However, examples of systemic implementation are confined to smaller regions notably in Catalonia (Spain), Scotland and Singapore. This reflects the fact that the implementation of integrated care is problematic at scale. The need to attend to methods that support high autonomy professionals tasked with local implementation (the 'who') is a neglected area. This is especially important in light of the fact managerial and clinical leaders already have operational and clinical imperatives to attend to. Whilst ideologically committed, the change management challenge presented by integrated care is daunting as they may lack the capacity (time, resources, structures) required to test a new care model. In addition, most change methodologies fail to recognise powerful social dynamics that reflect the characteristics of a complex adaptive system (the 'how'). This paper proposes a framework to implementing integrated care for older persons. In addition, it offers some initial empirical evidence that this approach has utility among managers and clinicians. In doing so seeks to bridge the implementation gap associated with systemic change.
\end{abstract}

Keywords Implementation $\cdot$ Integrated care $\cdot$ Managers and clinicians

The original version of this article was revised: author's belated corrections.

Patrick John Harnett

pjharnett.sdu@hse.ie

Extended author information available on the last page of the article 


\section{Background}

The aging population is a 'game changer' for health and social care provision (Oliver et al. 2014; Prince et al. 2015; Bloom et al. 2014). Multi-morbidities increase with age resulting in greater health and social care consumption. There is increasing insight into a 'high need, high cost' population, whereby a cohort of the older population (5\%) utilise between $27 \%$ and $50 \%$ of resources (Bluementhal et al. 2016). Integrating care is consequently proposed as a policy solution internationally (Hendry 2015; Berglund et al. 2015; Keong et al. 2013; Carswell 2015; Pike and Mongan 2014). Whilst there is growing evidence on 'what works' in improving discrete aspects of care for older persons (Davies et al. 2011; Ellis et al. 2011; Stokes et al. 2015; Parker et al. 2002; Mitchell et al. 2015; Gullery and Hamilton 2015; Stewart et al. 2013; Goodman et al. 2012; Wodchis et al. 2015; Nolte 2012; Trivedi et al. 2013; Coffey et al. 2015; Roland et al. 2012; Davies et al. 2011; Goodwin and Smith 2011; Stewart and Georgiou 2013; Bodenheimer and Berry-Millet n.d.; Boult et al. 2011; Lyon et al. 2007; Hutt et al. 2004; Boult et al. 2011; Counsell et al. 2007; Naylor et al. 2004) it is less clear 'how' best to implement integrated care systemically (Goodwin 2013; Valentijn 2015; Klinga et al. 2016). Systemic change is typically centrally defined but implementing 'top-down' change is problematic, delivering less than anticipated (Best et al. 2012; Greenhalgh et al. 2009). Equally, emergent ('bottom up') approaches have inherent weaknesses, not least the ability to ensure consistency at scale (Ham and Walsh 2013). In reality however, the people tasked with implementation are operational and clinical leaders with a 'day job'. Whilst they have the ability, they usually lack capacity (knowledge, time, resources, structures) to deliver the desired change. This paper proposes a rationale for using a framework approach rather than detailed care models to implement integrated care. In doing so, it draws on the critical ingredients necessary to integrate care, 'the what' and lessons from improvement in healthcare (Ovretveit 2011; Greenhalgh et al. 2009; Greenhalgh et al. 2012; Massoud et al. 2016; Valentijn et al. 2016; Dixon-Woods et al. 2011), 'the how'. This seeks to bridge the implementation gap. Early empirical evidence on the utility of this approach are presented.

\section{Introduction}

People aged over 65 constitute $11.7 \%$ of the Irish population (CSO 2011). Life expectancy for females and males ( $>75 \mathrm{yrs}$ ) has respectively increased by $29 \%$ and by $39 \%$ in recent decades (Eurostat 2016). The $>65$ population is anticipated to grow $60 \%$ in the next 10 years with the 'older aged', (i.e. those $>85 \mathrm{yrs}$ ) set to double to 500,000 (See Fig. 1: Population Projections:). In common with other jurisdictions a $15 \%$ increase in resources will be requirement by 2021 the needs of those aged $>85$ years in order to 'stand still' (HSE 2016).

People aged $>65$ typically use $50 \%$ of acute hospital inpatient bed days (Department of Health and Children 2016) and projected increase in Bed Days Used (BDU) in acute hospitals alone (Fig. 2; Projected attendance, admission and bed days used (2016-2026)) is equivalent to building two 500 bed hospitals for the $>75$ demand alone in the next 10 years if the current model remains unchanged (Open App 2017). 


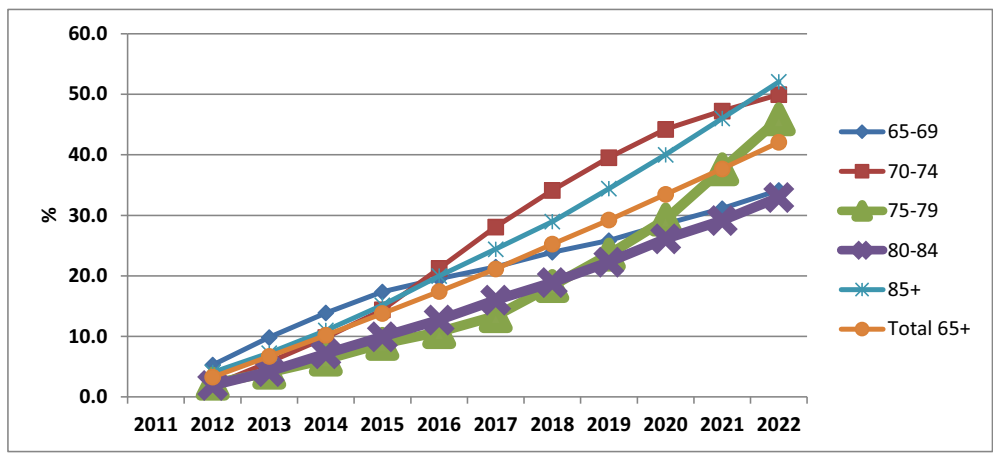

Fig. 1 Population projections

Aging brings an increased chance of long-term medical and social needs consequent to frailty (Halloran and A. 2017) and dementia (O'Shea 2015) and associated community cost (Smyth et al. 2016; Beard et al. 2016). There is recognition that increasing number of older persons will require greater provision due to compression of morbidity (Connors 2016). This, rather than gradual long term changes in age specific morbidity or mortality is a significant system challenge. Health and social care systems now recognise that sustainable strategies lie in a population-based approach with a focus on vulnerable cohorts. A compelling argument therefore exists to change the care delivery model to meet the needs of (older) people with complex, longitudinal care needs.

In this context, the Integrated Care Programme for Older Persons in Ireland (ICP OP) was tasked with developing a 'model' of integration care for older persons. There were multiple definitions of integrated care available (Kodener and Spreeuwenberg 2002) and the core design elements are well defined (Kodner 2009; Minkman 2015; Leutz 1999; Tsasis et al. 2012; Booker et al.

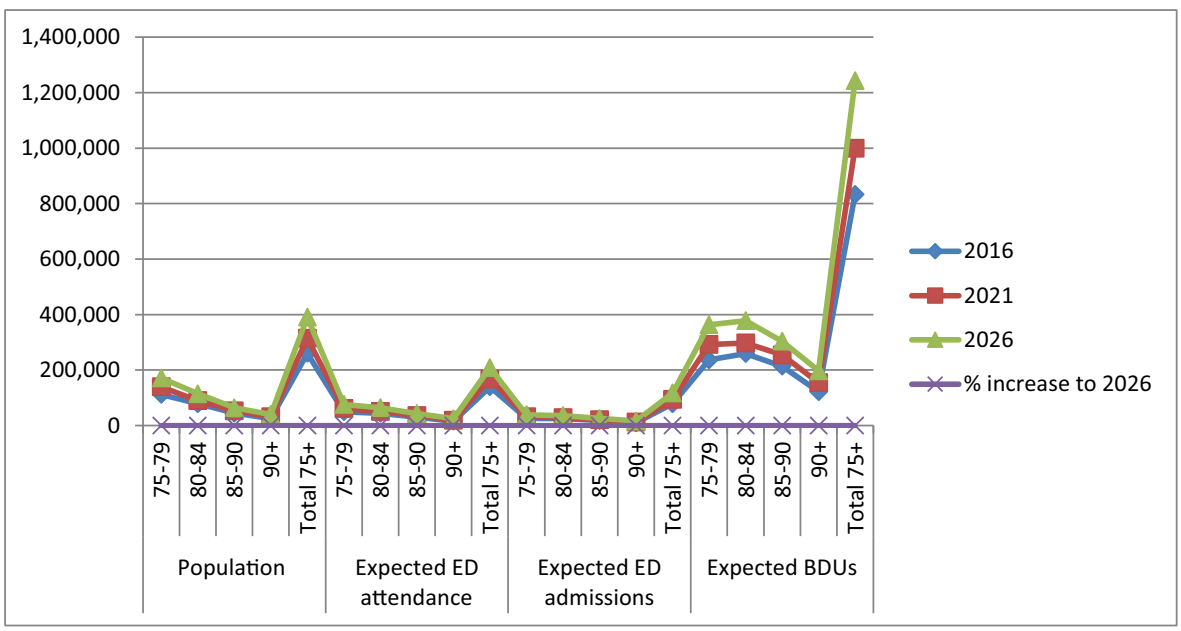

Fig. 2 Projected attendance, admission and bed days used (2016-2026) 
2015; Valentijn 2015). There is growing consensus on 'what works' (Fearon and Langhorne 2012; Hebert et al. 2003; Roland et al. 2012; Sheppard et al. 2013; Curry and Ham 2010 Dixon-_Woods et al 2012, Shortt et al 2016, Silvester et al 2014), with a consistent body of evidence based interventions. A literature review by the authors identified three key elements; (Harnett 2018);

1. A case management approach that assertively targets a vulnerable population and provides ease of access and care co-ordination.

2. Bespoke care pathways that are age attuned and facilitate rapid holistic assessment, community intervention and/or early supported discharge.

3. A multidisciplinary, interagency collaborative approach with a common assessment and shared care plan.

Whilst there is recognition that outcome attributable to integrated care are difficult to demonstrate, the evidence for key building blocks of integrated care (e.g. frailty attuned pathways) indicate improved outcomes for older people with complex care needs (Hendry 2015; Nolte 2012; Trivedi et al. 2013; Roland et al. 2012).

\section{Methods}

In advance of the ICP OP programme launch, an integrative literature review was conducted (Harnett 2018) to inform the ICP OP change methodology. A further literature reviews was undertaken using a rapid review approach (Khangura et al. 2012), synthesised the evidence on 'what worked best' in integrating care for older persons. The results of both literature reviews were captured in the ICP OP 10 Step Framework Integrated Care Framework in an iterative process. This was undertaken in consultation with members of the National Working Group, Older Persons by the authors. This group (8 members) had specialist expertise in both older persons and healthcare improvement. The framework was iteratively developed and represents a schematic conceptualisation of the key ingredients of integrating care.

The 10 Step Integrated Care Framework, Older Persons (Figs. 3), contains ten key design elements. This represents a roadmap for local leaders who can develop components incrementally by building on what's already in place. This is supported by national enablers (workforce, finance, evaluation, ICT) that are beyond local capacity. The framework includes key integration ingredients such as new ways of working (case management) and bespoke older person pathways (ambulatory or inpatient). The inclusion of supports to live well address the WHO initiative on Age Friendly City and Counties and facilitates coproduction. Underpinning this is a governance structure linking national and local decision making. This is in keeping with Nicholson et al. (Nicholson et al. 2016) who suggest that adopting design principles for governance in complex adaptive systems, combined with simple rules (to guide behaviour) offers a more promising way forward. 


\section{0-Step Integrated Care Framework for Older Persons}

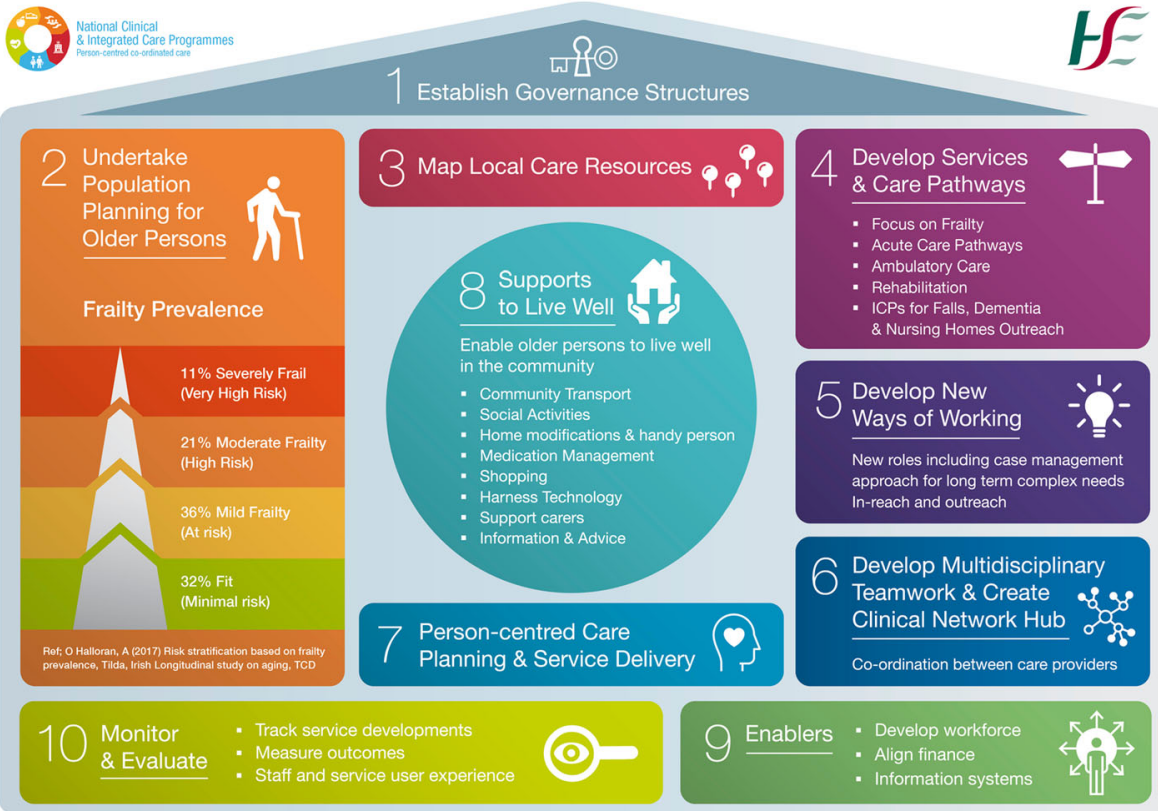

Fig. 3 ICP OP 10 Step Framework to Integrate Care for Older Persons

\section{The Challenge of Implementation}

Implementation of systemic, strategic change is a source of significant debate in healthcare as there is uncertainty about 'what work' (Ovretveit et al. 2011), particularly at a systemic level (Greenhalgh et al. 2009; Greenhalgh et al. 2012). The problem of context (political ideology, professional groups and organisational complexity) has been recognised for some time (Mc Adam (2008). Applying improvement methods (such as Lean Six Sigma) works in specific contexts (labs, radiology) but is not sufficient for systemic change (Radnor and Osbourne 2012). In order to operationalize systemic improvement, (the how) Ovretveit (2011) suggests there is need to create the conditions for improvement. This includes necessary incentives and enablers (finance, technology and evaluation) and adopting the appropriate change methodology. By extension, implementing integrated care is a complex task, requiring integration to take place at a macro (system), meso (organisational) and micro (clinical) level (Valentijn et al. 2013).

International experience indicates there is no 'off the peg' model of integrated care, suggesting in turn there is no uniform 'approach' to implementing integrated care. Mc Adams (2008) systematic review of frameworks to integrate care to older people offers a useful summary of the raw materials for integration. Her intention however, was to compare the critical components necessary rather than offer insights into the 'how' of implementation. (Valentijn 2015) Rainbow Model of Integrated Care (RMIC) and offers a shared conceptual understanding whilst Minkmans' (2015) Developmental Model of Integrated Care (DMIC) describes the combination of attributes and behaviours necessary to make integration functional. (Leijten et al. 2018) framework provides a comprehensive compendium of key ingredients that are suggested to aid 
conceptualisation, implementation and evaluation. This model adds a layer of implementation detail to the RMIC and DMIC but highlights that it is not a 'recipe for (implementing) reform'. Valentijn et al. (2013) suggests that normative forces (cultural/ professional/political dimensions) have a profound impact on implementation and suggested that integrated care is "an 'art form' founded on a colourful pallet of values and perceptions arising from several political, organisational, professional and clinical fields". In essence, Valentijn et al. (2013) were describing a Complex Adaptive System (CAS).

This is typically defined as a system composed of independent agents where the dominant property is one of emergence (rather than design, typified by a single point of control) and whose behaviour is significantly influenced by social rules (Begun et al. 2002). As a consequence, change methodologies in CAS are more responsive to 'nudges' (Halpern 2015) rather than traditional programmatic management. This is a critical starting point in choosing the implementation methodology in designing and implementing integrated care (Holden 2005; Evans et al. 2016; Leviton 2011; Benson 2005; Anderson et al. 2011; Booth et al. 2013) and significant point of difference when working with high autonomy professional networks. This recognises that change/ improvement efforts are embedded in complex social systems, whose actors are highly autonomous and whose views are influenced by powerful, shared professional narratives. In that context, is crucial that insights into achieving change in powerful sociotechnical systems offered by Rouse (2008) and Edgren and Barnard (2009) is essential. Taking this context for change on board, (Mc Farlane et al. 2013) review of systemic change describes coercive, normative and mimetic environmental pressures when seeking to change a 'system'. This combination of organisational sanction (regulatory), professional authorisation (moral) and culturally supported (normalized) provides some of the key rationale for a framework approach.

\section{Results}

A survey was conducted among 220 managers and clinicians directly and indirectly involved in implementing integrated care for older persons utilising the ICP OP Framework. A response rate of 80 (36\%) was received. Of those 50 responses were fully complete. Each factor comprising the 10 step framework was assessed for internal reliability or internal consistency, using Cronbach's' Alpha. A cut-off of 0.7 was achieved for each factor excluding Population, Technology and Collaboration. Both Population and Technology achieved a Cronbach's' Alpha which exceeded 0.6, and this can be considered an absolute minimum threshold (in light of the small number of indicators in each of these two constructs). The utility of the framework was considered and compared across a number of dimensions. One of the key areas of enquiry involved testing the perceived utility of a framework jointly expressed by managers and clinicians (Fig. 4: Managers and clinicians shared perception on the utility of the 10 step framework).

When asked to rate the utility of the framework across each dimension a broad level there was very strong support for each, Fig. 5: Strength of agreement on utility of the framework. However, the weakest component (governance) was potentially reflective of the lack of familiarity with and challenge in working across organisations. However, 


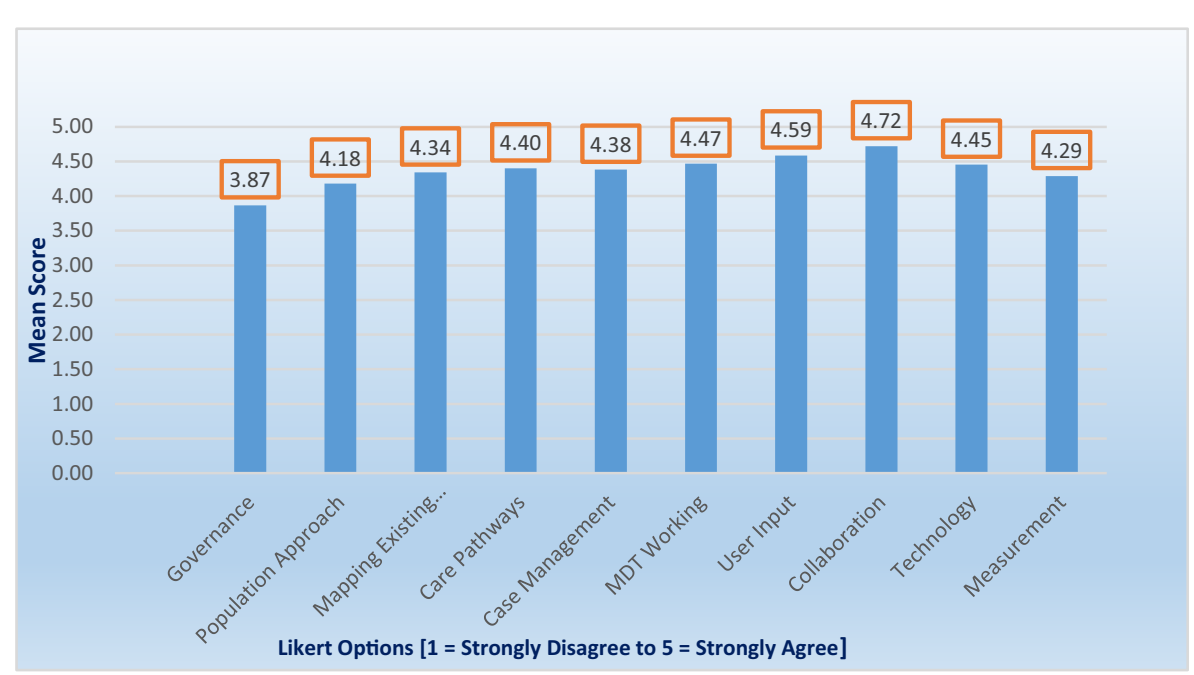

Fig. 4 Managers and clinicians shared perception on the utility of the 10 -Step Framework $(n=50)$

respondents appeared to understand the importance of collaboration and all rated the components $\geq 4$ (agree or strongly agree) with the exception of Governance. This was consistent across both groups but also more weakly rated as indicated in, Utility of the 10 step framework (managers $V$ clinicians) (Fig. 5).

Whilst one might typically expect one group to emphasise certain aspects over others there was strong consensus between the two groups on each framework element. This is important given the perceived divergence between managerial and clinical agendas.

A Spearman's rank-order correlation was run to assess the relationship between Governance and other framework elements (see Table 1: Correlation between framework elements). There was a moderate positive correlation between Governance and Population Planning, rs $(50)=.474, p<.01$. A Spearman's correlation of +.474

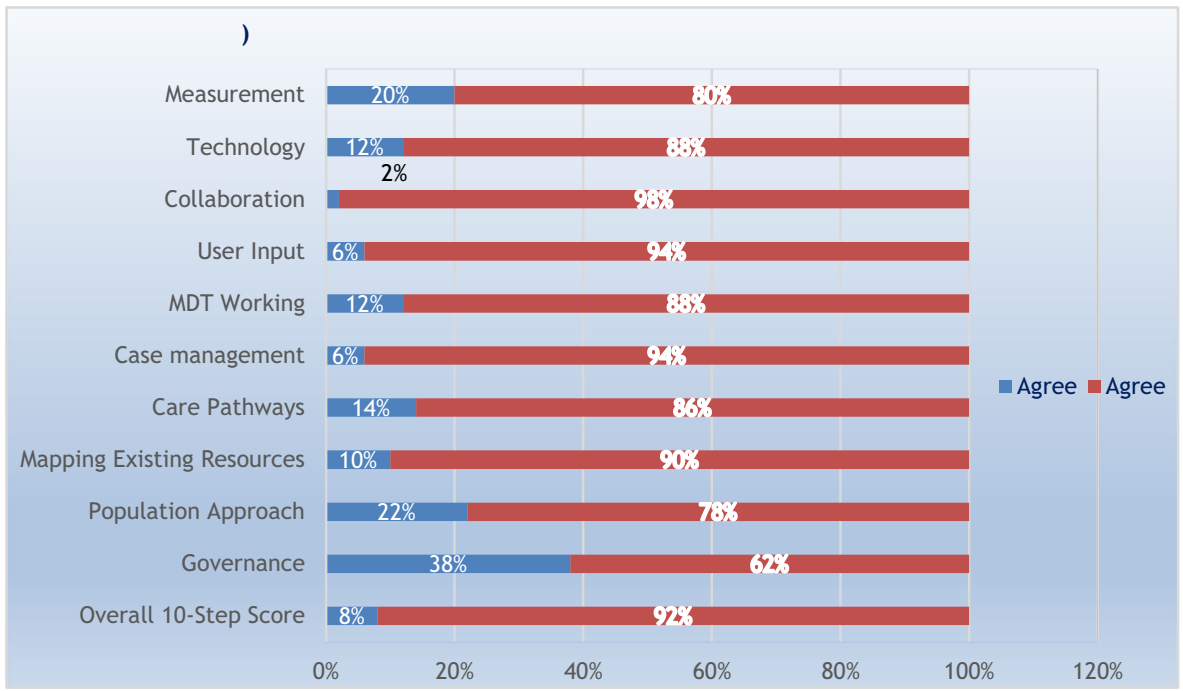

Fig. 5 Strength of agreement on utility of 10-Step Framework $(n=50)$ 
Table 1 Shared perception (clinicians and managers) on correlation between framework elements

\begin{tabular}{|c|c|c|c|c|c|c|c|c|c|c|}
\hline$n=50$ & Governance & Pop $^{n}$ & Mapping & $\begin{array}{l}\text { Care } \\
\text { Path }\end{array}$ & $\begin{array}{l}\text { Case } \\
\text { Mngt }\end{array}$ & MDT & $\begin{array}{l}\text { U s e r } \\
\text { Input }\end{array}$ & Collab & Tech & Measure \\
\hline Governance & $1^{1}$ & - & - & - & - & - & - & - & - & - \\
\hline Pop $^{n}$ & $.476^{* *}$ & 1 & - & - & - & - & - & - & - & - \\
\hline Mapping & $.359 *$ & $.689 * *$ & 1 & - & - & - & - & - & - & - \\
\hline Care Path & .012 & .270 & $.383 * *$ & 1 & - & - & - & - & - & - \\
\hline Case Mngt & .121 & .229 & .206 & .237 & 1 & - & - & - & - & - \\
\hline MDT & .203 & $.470 * *$ & $.435 * *$ & $.350^{*}$ & $.384 * *$ & 1 & - & - & - & - \\
\hline User Input & .131 & $.385^{* *}$ & $.312 *$ & .202 & .099 & .144 & 1 & - & - & - \\
\hline Collab & $.306^{*}$ & $.472 * *$ & $.372 * *$ & $.292 *$ & .202 & $.458^{* *}$ & $.401 * *$ & 1 & - & - \\
\hline Tech & .096 & .245 & $.343 *$ & $.361 * *$ & .068 & .228 & .178 & $.295 *$ & 1 & - \\
\hline Measure & -.040 & $.441 * *$ & $.352 *$ & $.289 *$ & .132 & $.421 * *$ & $.365 * *$ & .264 & $.426^{* *}$ & 1 \\
\hline
\end{tabular}

* Correlation is significant at the 0.05 level (2-Tailed)

** Correlation is significant at the 0.01 level (2-Tailed)

${ }^{1}$ The value of 1 in the diagonal represents a perfect association between any one variable against itself. The points in such a chart would be represented by a straight line, with each coordinate on the line

indicates that there was $47.4 \%$ positive association between the two variables (Governance \& Population planning). Similar patterns can be observed for other areas such as population planning and resource mapping (Table 1).

On deeper exploration, the Mann-Whitney $\mathrm{U}$ test indicated that younger managers and clinical leaders $(<45)$ are $67 \%$ more likely to record a higher score compared to the older age group $(\geq 45)$ (Fig. 6).

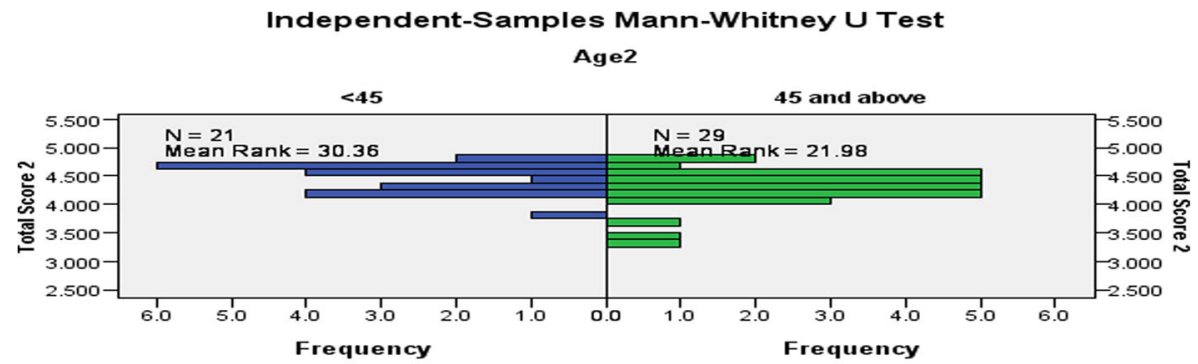

\begin{tabular}{|lr|}
\hline Total N & 50 \\
\hline Mann-Whitney U & 202.500 \\
\hline Wilcoxon W & 637.500 \\
\hline Test Statistic & 202.500 \\
\hline Standard Error & 50.869 \\
\hline Standardized Test Statistic & -2.005 \\
\hline Asymptotic Sig. (2-sided test) & .045 \\
\hline
\end{tabular}

Fig. 6 Comparison between respondents $<45$ or $>45$ yrs 
A similar comparison was made in terms of differences in the average score (overall score) of less experienced $(<20)$ versus more experienced $(\geq 20)$ respondents.

Distributions of the 10-Step scores between groups with $<20$ and $\geq 20$ years experience were similar, as assessed by visual inspection. Median 10-Step scores was statistically significantly higher in the group with $<20$ years experience (4.55) compared to the group with $\geq 20$ years experience (4.33), $\mathrm{U}=189.5, \mathrm{z}=-2.188, p=.029$. In summary, the less experienced group $(<20)$ are $67 \%$ more likely to record a higher perceived Total 10 Step score compared to the more experienced group $(\geq 20)$. When responses were compared across the framework elements respondents that expressed high scores (meaning agreement) in Governance also tended to expressed high scores in population planning and by definition respondents that expressed lower scores (a lower degree of agreement or disagreement) in Governance also expressed tended to express lower scores (a lower degree of agreement or disagreement) in population planning (Fig. 7).

A broader indication of the utility of the approach is the number of new sites that are getting involved. Whilst 6 pioneer areas were included in the initial phase of the pilot, this has incrementally grown through self-selection of sites who see the opportunity to redesign services and develop business cases proposing their inclusion (Fig. 8).

\section{Discussion}

In the messy reality of highly pressurised healthcare environments, the clinical and managerial leaders tasked with delivering change are doing so with competing operational imperatives. The task of implementation is an 'add on' to their operational or clinical role, typically without project management support. However, their ownership and local knowledge puts them in a much better position to act than any centrally

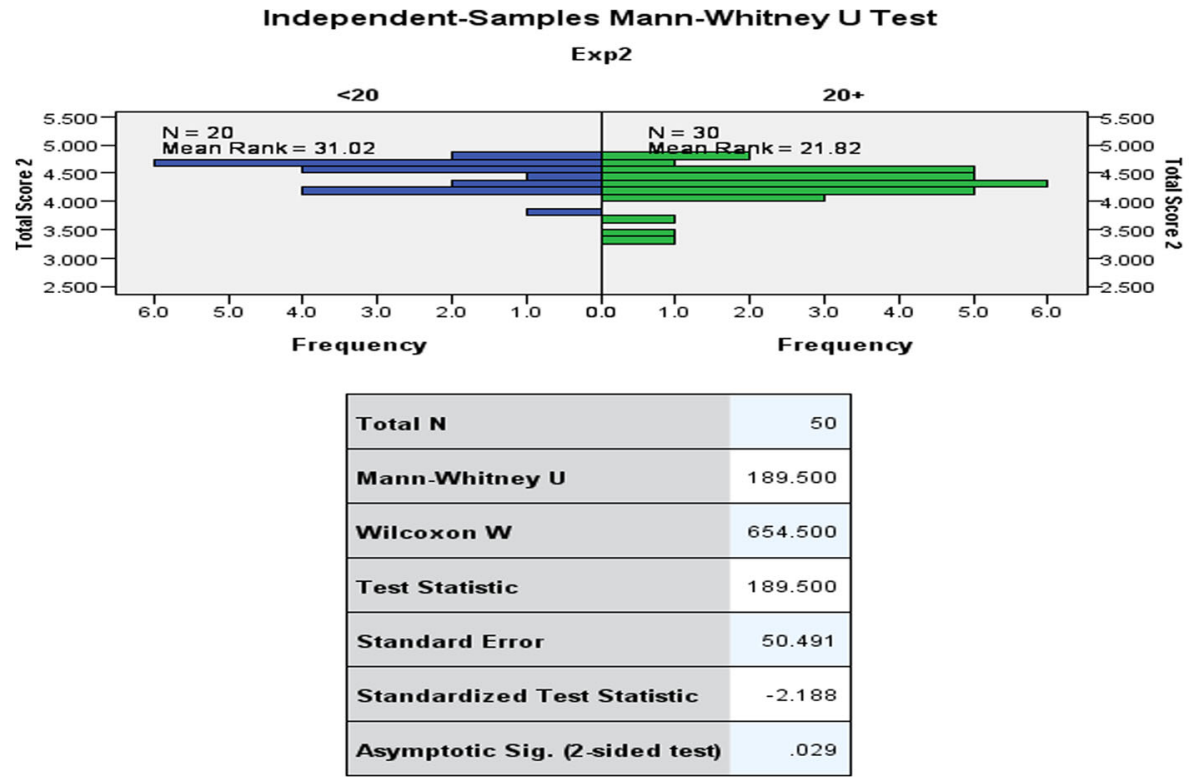

Fig. 7 Comparison between respondents $<20$ or $>20$ yrs. experience 


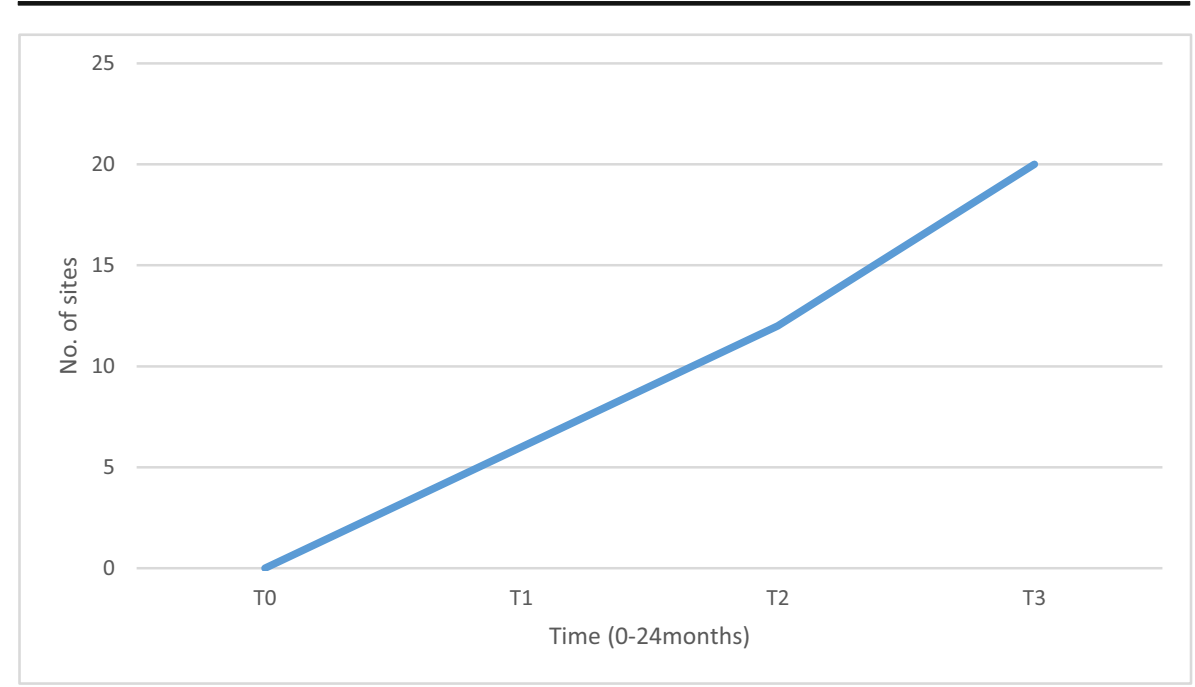

Fig. 8 Increase in pioneer sites (2016-2018)

dictated model or change management process could achieve. Whilst it's not possible to elaborate on each of the underpinning theories, the development of the ICP OP 10 Step Framework not only accommodates complexity theory but draws on a rich range of interdisciplinary insights such as organisational development (Cooperrider 2000), personal agency (May 2013) and motivational theory (Seligman and Seligman 1991). In particular, a framework approach reflects a social-cognitive approach offered by Bandura (Bandura 2000a, b, 2001). Whilst Banduras theory of self-efficacy was originally applied at individual health behaviour level, subsequent application (Bandura 2000b) focused on a socio-cultural context. In drawing on social cognitive theory as an approach to implementation, agents with self-efficacy act on opportunities when presented. In accordance with behavioural and psychological insights, social cognitive theory proposes that behavioural change is enhanced by a personal sense of control. If people believe that they can take action to solve a problem instrumentally, they become more inclined to do so and feel more committed to the decision.

The logic that underpins the proposed (10 Step) framework approach not only draws on lessons from whole system transformational change but also recognises the hidden cultural dimensions (Bate 2004; Buchanan 2003), particularly the role of institutional healthcare entrepreneurs (Breton et al. 2014; Locket et al. 2012). The provision of a framework allows for structural and normative legitimacy, which confers increased agency on local leaders. Indeed, Muskat and Sylvester (2012) indicate that individual social entrepreneurs are an unstoppable force of social change with a multiplying effect when social entrepreneurs come together to solve problems collectively. Collaborative entrepreneurship within a framework approach therefore leverages local resources and networks to scale social innovations more effectively. This complex dynamic is reflected in; Fig. 9 (Dynamics of a Complex Adaptive System in implementation) where best practice, organisational requirements for accountability and the process of integrating care interact, with various 'actors' perception of personal/professional agency playing a crucial part (Fig. 9).

Whilst there is a need to cultivate local innovation and entrepreneurship, there is also a need to ensure consistency in terms of the 3 key design elements ('what works'). 


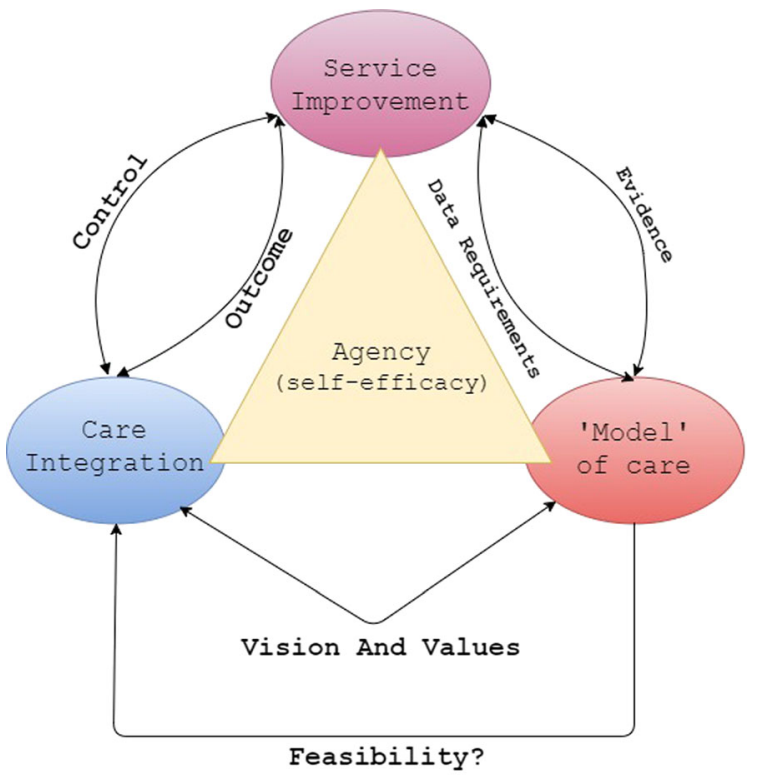

QPJ Harnett (2016)

Fig. 9 Dynamics of a CAS in implementation

These 'hard edges' need to be deployed consistently but allow for local contextual nuances. This accommodates existing resources, historic service development and local capacity and capability. This is in keeping with Ling et al. (2012) who recognises the impact of professional social networks which builds incrementally through small scale local successes. This is best exemplified by the work emerging in one of the pioneer sites, Cooke (2018) whereby a modest resource invested allowed an amplification of service development with tangible service benefits (Fig. 10).

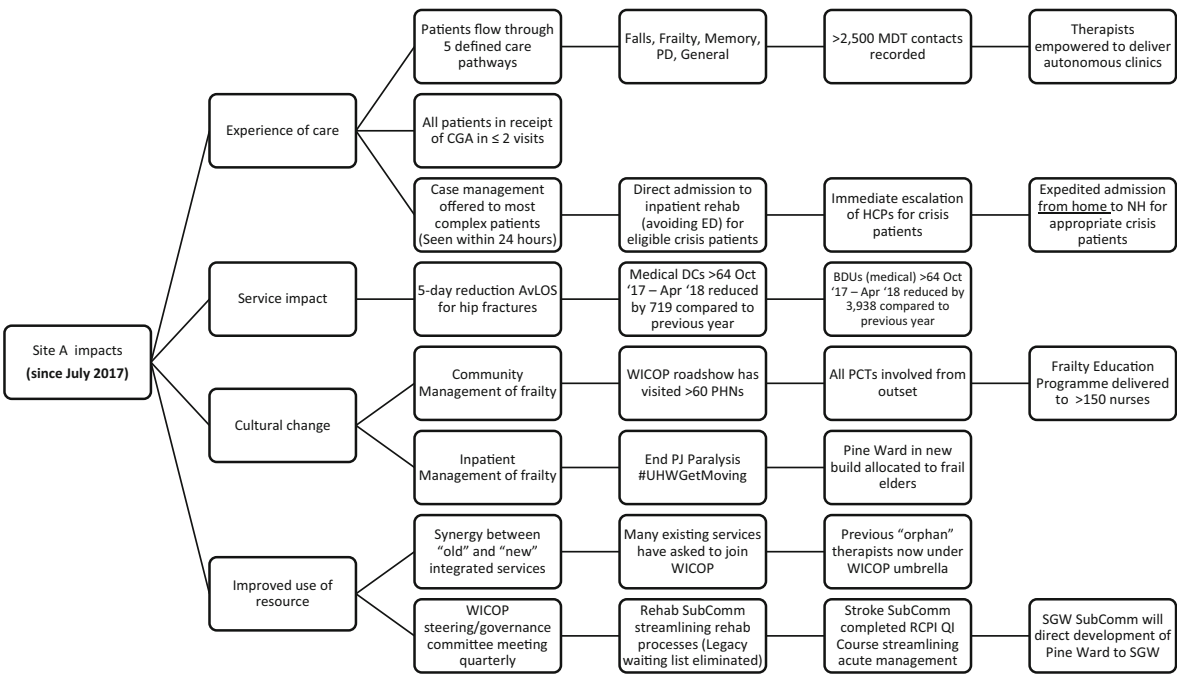

Fig. 10 'Ripple' effect of integrated care in a local health economy 
Whilst a framework sets out a broad direction of travel (capturing the conceptual vision), its primary function is to facilitate a means by which individual and institution interests might be aligned towards implementation. It is not stringently imposed (as 'the model') but does contain the fundamentals and seeks to recognise the lived reality of implementing change for managers and practitioners. In that regard a framework approach not only builds commitment and ownership, it simultaneously accommodates regulatory components (such as evidence based care pathways developed by clinical programmes), normative influence (shared best practice across innovative networks) and a cultural-cognitive aspect endorsing, 'what good care ought to look like'. The fact that they have control over local design but supported and witnessed nationally is crucial. This enables agents participating in ICP OP to see themselves as part of an innovation (national and local) with potential to realise personal/professional ambition. In this regard, the CAS approach satisfies the fundamental human need not only to participate but to feel one is part of a greater whole (Fig. 9).

\section{Conclusions}

Integrated care, embedded in a population approach, is a well-established, international policy response to growing complexity and multi-morbidity associated with an ageing demographic. The improvement challenge in integrated care is significant and therefore requires an epistemological shift that recognises implementation taking place in a complex adaptive system. This requires the selection of the appropriate change methodology which recognises the importance of professional socio dynamics. All of this is heavily contingent on meaningful engagement with high autonomy practitioners as codesign partners. A framework approach appears to offer an operationally useful means by which critical design and enabling elements can be deployed by local leaders who are not experts in integration design and implementation. However, a framework appears to facilitate a common architecture that enables 'direction without dictat'.

It was not the intention of this paper to provide a comprehensive, evidence base rationale for each element step or the underpinning psychological theories associated with the framework. What is proposed is that the ICP OP framework approach offers two things simultaneously. In the first instance, in common with RMIC, SELFIE and DMIC, it offers a means of allowing all agents involved (locally and nationally) to share a common conceptual map of what 'good' looks like in integrating care for older persons. This in turn facilitates an understanding of their respective clinical and organisational contributions and enables innovative, flexible local design to be set within a national common context that includes evaluation, technology and resource. Secondly, it provides a means by which local leaders can mobilise service redesign. This facilitates a shared social construct around what a national 'model' might look like whilst allowing for local variation. In doing so it recognises the complexity context and provides direction without dicat. The early findings suggest this approach holds promise as a means of mobilising systemic change.

Acknowledgements The authors wish to acknowledge the contribution of the National Working Group, HSE who contribute to the development of this framework; Ms. Dee Conroy, Professor Emer Shelley, Dr. D. O' Shea, Ms. H Whitty, Ms. D Lange, Ms. C Hoey, Mr. J Brennan, Mr. D. Mulligan, Ms. J Hardiman. 
Authors' Contributions The content of this article is the work of the joint authors with the contribution of others acknowledged. Both authors read and agreed the final manuscript.Data AvailabilityThe data used in this publication is available on reasonable request from the corresponding author.

\section{Compliance with Ethical Standards}

Conflict of Interest Neither of the authors received funding or have any competing interests associated with the production of the framework or this article.

Ethical Treatment of Experimental Subjects (Animal and Human) This study complied with ethical requiremnts and sought informed consent from participants

Open Access This article is distributed under the terms of the Creative Commons Attribution 4.0 International License (http://creativecommons.org/licenses/by/4.0/), which permits unrestricted use, distribution, and reproduction in any medium, provided you give appropriate credit to the original author(s) and the source, provide a link to the Creative Commons license, and indicate if changes were made.

\section{References}

Anderson, R., Crabtree, B., Steel, D., \& Mc Daniel, R. (2011). 'Case Study Research: The View from Complexity Science. Qualitative Health Research, 15(5), 669-685.

Bandura, A. (2000a). Exercise of human agency through collective efficacy. Current Directions of Psychological Science, 9, 75-78.

Bandura, A. (2000b). Cultivate self-efficacy for personal and organizational effectiveness. In E. A. Locke (Ed.), The Blackwell Handbook of Principles of Organizational Behavior (pp. 120-136). Oxford: Blackwell.

Bandura, A. (2001). Social cognitive theory: An agentic perspective. Annual Review of Psychology, $52,1-26$.

Bate, P. (2004). The role of stories and storytelling in organizational change efforts: The anthropology of an intervention within a UK hospital. Intervention Research, 1(1), 27-42.

Beard, J., Alana Officer, A., de Carvalho, I., Sadana, R., Pot, A. M., Michel, J. P., Lloyd-Sherlock, P., EppingJordan, J., Peeters, G., Mahanani, W. R., Thiyagarajan, J. A., \& Chatterji, S. (2016). The world report on ageing and health: A policy framework for healthy ageing. Lancet, 387, 2145-2154.

Begun, J. W., Zimmerman, B., \& Dooley, K. (2002). Health care organizations as complex adaptive systems. In S. Mick \& M. Wyltenbach (Eds.), Advances in Health Care Organization Theory (pp. 253-288). San Francisco: Jossey-Bass.

Benson, H. (2005). Chaos and complexity: Applications for healthcare quality and patient safety. Journal of Healthcare Quality, 27(5), 4-10.

Berglund, H., Blomberg, S., Duner, A., \& Kjellgren, K. (2015). Organising Integrated care for older persons: strategies in Sweden during the past decade. Journal of Health Organisation and Management, 29(1), 128-151.

Best, A., Greenhalgh, T., Lewis, S., Saul, J. E., Carroll, S., \& Bitz, J. (2012). Large-system transformation in health care: A realist review. Milbank Quarterly, 90(3), 421-456.

Bloom, D., Chatterji, S., Kowal, P., Lloyd-Sherlock, P., McKee, M., Rechel, B., Rosenberg, L., \& Smith, J. (2014). Macroeconomic implications of population ageing and selected policy responses. The Lancet, 385(9968), 577-662.

Bluementhal, D., Cherof, B., Fulmer, T., Lumpkin, J., \& Selberg, J. (2016). Caring for high cost high need patients. An urgent priority. New England Journal of Medicine, 375, 909-909.

Bodenheimer, T., \& Berry-Millet, R. Care Management of Patients with complex health care needs, research synthesis report no. 19. Princeton: Robert Wood Johnson Foundation Dec, 2009.

Booker, C., Turbutt, A., \& Fox, R. (2015; Apr). Models of care for a changing healthcare system: are there foundational pillars for design? Australian Health Review, 40(2), 136-140.

Booth, B. J., Zwar, N., \& Harris, M. F. (2013). Healthcare improvement as planned system change or complex responsive processes? A longitudinal case study in general practice. BMC Family Practice, 14, 51-62. 
Boult, C., Reider, L., \& Leff, L. (2011; March). The Effect of Guided Care Teams on the Use of Health Services: Results from a Cluster-Randomized Controlled Trial. Archives of Internal Medicine, 171(5), 460-466.

Breton, M., Lamonthe, L., \& Denis, J. L. (2014). How Healthcare Organisations can act as institutional entrepreneurs in a context of change. Journal of Healthcare Management, 28(1), 77-95.

Buchanan, D. A. (2003). Getting the story straight: Illusions and delusions in the organizational change process. Tamara Journal of Critical Organisation Inquiry, 2, 7-21.

Carswell, P. TeWhiringa Ora: person-centred and integrated care in the Eastern Bay of Plenty, New Zealand, Special issue, International Journal of Integrated Care, Integrating care to older people and those with complex needs, Examining the lessons from International care studies, 2015;Vol. 16, (6), pp.

Coffey, A., Leahy-Warren, P., Savage, E., Hegarty, J., Cornally, N., Day, M. R., Maher, B., Browne, J., Sahm, L., O’Caoimh, R., Flynn, M., Hutton, S., O’Mahony, A., \& Arenella, K. (2015). A Systematic Literature Review on Tackling Delayed Discharges in Acute Hospitals Inclusive of Hospital (Re) admission Avoidance. Dublin: Department of Health and children.

Connors, J. (2016). Irelands changing demographic profile; implications for public expenditure. Irish Government evaluation of Expenditure: Department of Public.

Cooke, J. (2018) Waterford Integrated Care Older Person, Network Day Presentation, www.wicop.ie (reproduced with permission).

Cooperrider, D. (2000) Collaborating for change, published by Phoenix books, Essex.

Counsell, S. R., Callahan, C. M., \& Clark, D. (2007; Dec). Geriatric Care Management for Lowincome Seniors: A Randomized Controlled Trial. Journal of the American Medical Association, 298(22), 2623-2633.

CSO (2011) http://www.cso.ie/en/census/census2011reports. (Accessed 5.12.16).

Curry, N. Ham, C. Clinical and service Integration. The route to improved outcomes, 2010; The Kings Fund London,

Davies, S., Goodman, C., Bunn, F., Victor, C., Dickinson, A., Iliffe, S., Gage, H., Martin, W., \& Frogatt, K. (2011). A systematic review of integrated working between care homes and health care services. $B M C$ Health Services Research, 11, 320.

Department of Health and Children, (2016) Health in Ireland, Key Trends, Department of Health.

Dixon-Woods, M., Bosk, C. L., Aveling, E. L., Goeschel, C. A., \& Pronovost, P. J. (2011). Explaining Michigan: Developing an ex post theory of a quality improvement program. Milbank Quarterly, 89(2), $167-205$.

Dixon-Woods, M., McNicol, S., \& Martin, G. (2012). Ten challenges in improving quality in healthcare: Lessons from the Health Foundation's programme evaluations and relevant literature. BMJ Quality and Safety, 21, 876-884.

Edgren, L. Barnard, K. (2009) Applying a complex adaptive system approach to the management of integrated care, Conference abstract, International Journal of Integrated Care, Applying a complex adaptive systems approach to the management of integrated care,

Ellis, G., Whitehead, M. A., Robinson, D., O’Neill, D., \& Langhorne, P. (2011; Oct 27). Comprehensive geriatric assessment for older adults admitted to hospital: meta-analysis of randomised controlled trials. BMJ, 343 .

Eurostat (2016) http://ec.europa.eu/eurostat/web/population-demography-migration-projections/deaths-lifeexpectancy-data (Accessed 5.12.16).

Evans, J., Grudniewicz, A., Ross Baker, G., \& Wodchis, W. (2016). Organisational context and capabilities for integrating care. International Journal of Integrated Care, 16(3), 15.

Fearon, P., \& Langhorne, P. (2012; Sep). Services for reducing duration of hospital care for acute stroke patients. Cochrane Database Systematic Review, 12(9).

Goodman, C., Drennan, V., Manthorpe, J., Gage, H., Travedi, D., Shah, D., Shabel, F., Poltowski, L., Handly, M., Nash, A., \& Ififfe, S. (2012). A study of the effectiveness of interprofessional working for community dwelling older people. Final Report, NIHR, Service delivery and organisation Programme. NHS.

Goodwin, N. (2013). Understanding integrated care, a complex process, a fundamental principle. International Journal of Integrated Care, 13(1).

Goodwin, N. Smith, J. (2011). The evidence base for integrated care, resource pack, the kings fund, https://www. kingsfund.org.uk/sites/files/kf/Evidence-base-integrated-care2.pdf, 2011; (Accessed 12.5.16).

Greenhalgh, T., Humphrey, C., Hughes, J., MacFarlane, F., Butler, C., \& Pawson, R. (2009). How do you modernize a health service? A Realist Evaluation of Whole-Scale Transformation in London. Milbank Quarterly, 87, 391-416.

Greenhalgh, T., MacFarlane, F., Barton-Sweeney, C., \& Woodard, F. (2012). If we build it, will it stay?' A Case Study of the Sustainability of Whole-System Change in London. Milbank Quarterly, 90, 516-547. 
Gullery, C., \& Hamilton, G. (2015). Towards integrated person centred-care, the Canterbury experience. Future Hospital Journal, 2(2), 111-116.

Halloran, O., \& A. (2017). Risk stratification based on frailty prevalence, Tilda. Trinity College Dublin: Irish Longitudinal study on aging.

Halpern, D. (2015). Inside the nudge unit, how small change can make a big difference. Published by WH Allen.

Ham, C., \& Walsh, N. (2013). Making integrated care happen at scale and pace, lessons from experience. Kings Fund London.

Harnett, PJ. (2018) Improvement attributes in healthcare; implications for integrated care (accepted and in press, International Journal for Quality Assurance in Healthcare ).

Hebert, R. Durand, P. Dubuc, N. Touringy, A. PRISMA: a new model of integrated service delivery for the frail older people in Canada. International Journal of Integrated Care, 2003;Jan-March.

Hendry, A. (2015). Reshaping Care Pathways for Older People, Joint Improvement Team. Scotland: Conference Presentation.

Holden, L. M. (2005). Complex adaptive systems: Concept analysis. Journal of Advanced Nursing, $52,651-657$.

HSE (2016) National Service Plan, www.hse.ie/eng/services/publications/corporate/sp2015.pdf (Accessed 4.1.16).

Hutt, R., Rosen, R., \& McCauley, J. (2004). Case-managing long-term conditions: What impact does it have in the treatment of older people? London: The King's Fund.

Keong, H. Mun, W. Feng, L. Huang, J. Cheah, J. Singapore programme for integrated care for the elderly, International Journal of Integrated Care, 2013; July-Sept (12) Supp. 13.

Khangura, S., Konnyu, K., Cushman, R., Grimshaw, J., \& Moher, D. (2012). Evidence summaries: The evolution of a rapid review approach. Systematic Reviews, 1, 10.

Klinga, C., Hansson, J., Hasson, H., \& Sachs, A. (2016; May 23). Co-leadership- A management solution to integrated health and social care. International Journal of Integrated Care, 16(2), 7.

Kodener, D., \& Spreeuwenberg, C. (2002). Integrated care, meaning, logic, application and implication, a discussion paper. International Journal of Integrated Care, 2.

Kodner, D. All together now, a conceptual exploration of integrated care, healthcare quarterly, 2009;special issue, Vol. 13, Oct,

Leijten, F. R. M., Struckmann, V., van Ginneken, E., Czypionka, T., Kraus, M., Reiss, M., \& Tsiachristas, A. (2018 Jan). Boland M ${ }^{6}$ de Bont A, Bal R, Busse R, Mölken MR; the SELFIE framework for integrated care for multi-morbidity: Development and description. Health Policy, 122(1), 12-22. https://doi. org/10.1016/j.healthpol.2017.06.002.

Leutz, W. (1999). Five laws for integrating medical and social services:lessons from the US and the United Kingdom. Millbank Quarterly, 77(1), 77-110.

Leviton, L. (2011). Reconciling complexity and classification in quality improvement research. BMJ Quality and Safety, 20, i25-i28.

Ling, T., Brereton, L., Conklin, A., Newbould, J., \& Roland, M. (2012). Barriers and facilitators to integrated care: experiences from the English Integrated Care Pilots. International Journal of Integrated Care, 12, $1-12$.

Locket, A., Currie, G., Waring, J., Finn, R., \& Martin, G. (2012). The role of institutional entrepreneurs in reforming healthcare. Social Science, 74, 356-363.

Lyon, D., Lancaster, G. A., Taylor, S., Dowrick, C., \& Chellaswamy, H. (2007). Predicting the likelihood of emergency admission to hospital of older people: Development and validation of the emergency admission risk likelihood index (EARLI). Family Practice, 24(2), 158-167.

Massoud, R. Barry, D. Murphy, A. Albrecht, Y. Sax, S. Parchman, B. M. How do we learn about improving healthcare, the call for a new epistemological paradigm. International Journal for Quality in Healthcare, 2016;April, 1-5.

May, C. (2013). Agency and implementation: Understanding the embedding of healthcare innovations in practice. Social Science and Medicine, 78, 26-33.

Mc Adam, M (2008) Framework of integrated care for the elderly: A systematic review, Canadian Policy Research Network, April.

Mc Cormack, B. Kitson, A. Harvey,G. Rycroft, J. Titchen, A. Seers, K. Getting evidence into practice: the meaning of 'context'. Journal of Advanced Nursing, 2002; 38, 1, pp 94-104.

Mc Farlane, F. Barton-Sweeney, C. Woodard, F. Greenhalgh, T. Achieving and sustaining profound institutional change in healthcare: Using neo-institutional theory. Social Science and Medicine, 2013;, 80,pp10-18.

Minkman, M. (2015) Effectively organising integrated care, the developmental model of integrated care, EU Observatory Summer school, 
Mitchell, G., Burridge, L., Zhang, J., Donald, M., Scott, I., Dart, J., \& Jackson, C. (2015). Systematic review of integrated models of health care delivered at the primary-secondary interface: How effective is it and what determines effectiveness. Australian Journal of Primary Care, 21(4), 391-408.

Muskat, E. Sylvester, D. Being disruptive, how open growth is delivering effective social change at a fast pace. Technology Innovation Management Review, (2012) July, 16-20.

Naylor, M. D., Brooten, A., \& Campbell, R. L. (2004; May). Transitional Care of Older Adults Hospitalized with Heart Failure: A Randomized, Controlled Trial. Journal of the American Geriatrics Society, 52(5), 675-684.

Nicholson, C., Jackson, C., \& Marley, M. (2016). A Governance Model for Integrated primary/secondary care for the health reforming first world- a systematic review. BMC, Health Services Research, 13, 528.

Nolte, E. (2012). National evaluation of the Department of Health Integrated Care Pilots. RAND Europe: Final report.

O'Shea, E. (2015). Prevalence and projections of dementia in Ireland. Mullingar: Report prepared for Genio Ltd.

Oliver, D., Foot, C., \& Humphries, R. (2014). Making our health and care system fit for an aging population. London: The Kings Fund.

Open App. ED attendance, admission and bed days used by people $>75$ yrs, Personal correspondence, 2017.

Ovretveit, J. (2011). Understanding the conditions for improvement: research to discover which context influences affect improvement success. BMJ Quality and Safety, 20, i18-ii2.

Ovretveit, J., Leviton, L., \& Parry, G. J. (2011). Increasing the generalisability of improvement research with an improvement replication programme. BMJ Quality and Safety, 20, i87-i91.

Parker, S. G., Peet, S. M., McPherson, A., Cannaby, A. M., Abrams, K., Baker, R., Wilson, A., Lindesay, J., Parker, G., \& Jones, D. R. (2002). A systematic review of discharge arrangements for older people. Health Technology Assessment, 6(4), 1-183.

Pike, B., \& Mongan, D. (2014). The integration of health and social care services. Ireland: Health Research Board.

Prince, M. J., Wu, F., Robledo, L., \& O’Donnell, M. (2015). The burden of disease in older people and implications for health policy practice. The Lancet, 385(9967), 549-562.

Radnor, Z., \& Osbourne, S. (2012). Lean. A failed theory for public services. Public Management Review, 13, 265-287.

Roland, M., Lewis, R., Stevenson, A., Abel, G., Adams, J., Bardsley, A., Breraton, L., Chitnis, X., Conklin, A., \& Staetsky, L. (2012). Case management for at-risk elderly patients in the English integrated care pilots: Observational study of staff and patient experience and secondary care utilisation. International Journal of Integrated Care, 12, 1-21.

Rouse, W. 'Healthcare as a complex adaptive system, Implications for Design and Management'; The Bridge, National Academy of Engineering, 2008; ol 28, No1, Spring.

Seligman, M., \& Seligman, M. E. P. (1991). Learned optimism. New York.

Sheppard, S. Lannin, N. Clemson, L. Mc Cluskey, C. Cameron, I. Barras, S. Discharge planning from hospital to home, Cochrane database of systematic reviews, 2013; Issue 1.

Shortt, J. O Malley, G. Heffernan, M (2016) Improving the quality of care for frail older people, Sligo University Hospital.

Silvester, K., Mohammed, M., Harriman, P., Girolami, A., \& Downes, T. (2014). Timely care for frail older people referred to hospital improves efficiency and improves mortality without the need for extra resources. Age and Aging, 4(43), 472-477.

Smyth, B. Kavanagh,P. Marsden, P. Donoghue, F. Kitching, A. Ryan, A. Cullen, C. (2016), Planning for health, projected demographic effect on health service costs 2017, Health and Wellbeing Division, Health Service Executive.

Stewart, M., Georgiou, A., \& Westbrook, J. (2013). Successfully integrating aged care services: a review of the evidence emerging from a long term care programme. International Journal of Integrated Care JanMarch, 13.

Stokes, J., Panagioti, M., Alam, R., Cheraghi-sohi, S., \& Bower, P. (2015). Effectiveness of case management for 'at risk' patients in primary care: A systematic review and meta-analysis. PLoS One, 10(7).

Trivedi, D., Goodman, C., \& Gage, H. (2013). The effectiveness of inter-professional working for older people living in the community: A systematic review. Health and Social Care in the Community., 21(2), 113-128.

Tsasis, P., Evans, J., Rush, L., \& Diamond, J. (2012). Learning to learn; towards a relational and transformational model for improved integrated care delivery. Administrative Sciences, 3, 9-31.

Valentijn, P. (2015). Rainbow of Chaos: A study into the Theory and Practice of Integrated Primary Care. International Journal of Integrated Care, 16(2).

Valentijn, P., Shepman, S., Opheji, W., \& Bruijnzeels, M. (2013; Jan-Mar). Understanding integrated care: a complex process, a fundamental principle. International Journal of Integrated Care, 13. 
Valentijn, P., Biermann, C., \& Bruijnzeels, M. (2016). Value based integrated (renal) care: Setting a development agenda for research and implementation strategies. BMC Health Services Research, 16, 330.

Wodchis, W., Dixon, A., Anderson, G., \& Goodwin, N. (2015). Integrating care for older people with complex needs: key insights and lessons from a seven-country cross-case analysis. International Journal of Integrated Care, 16, 6.

Publisher's Note Springer Nature remains neutral with regard to jurisdictional claims in published maps and institutional affiliations.

PJ Harnett has worked in a variety of roles in Healthcare over the past 34 years before becoming the National Programme Manager for the Integrated Care Programme Older Persons. This included working in clinical practice, senior managerial and service improvement and development roles locally and nationally. Originally qualifying as a Mental Health Nurse, he holds a Masters in Nursing, Masters in Healthcare Management and is currently undertaking a $\mathrm{PhD}$ in implementation of change in health systems with a specific focus on integrated care.

Dr. Siobhan Kennelly is a Consultant Geriatrician in Connolly hospital with over 20 years experience in Health Care. Dr. Kennelly is the clinical lead on the integrated care programme and has led many innovative projects in the area of dementia care, nursinh home outreach and technology enabled care. She holds an MB, $\mathrm{BCh}, \mathrm{BOA}, \mathrm{MSc}$, and is a Senior Lecturer in the RCSI.

Dr. Williams is a lecturer in operations management in the faculty of Research Engineering in University of Limerick. He teaches and has research interests in the area of the supply chain management, discrete event simulation and human factors of integration with application in healthcare. He holds a $\mathrm{BA}$ and $\mathrm{PhD}$ in engineering.

\title{
Affiliations
}

\section{Patrick John Harnett ${ }^{1} \cdot$ Siobhan Kennelly ${ }^{2} \cdot$ Peter Williams $^{3}$}

\author{
Siobhan Kennelly \\ siobhan.kennelly1@hse.ie \\ Peter Williams \\ peter.williams@ul.ie
}

1 Social Care Division/Clinical Strategy and Programme Division, Health Service Executive, Dublin, Ireland

2 Clinical Strategy and Programme Division/Social Care Division, Health Service Executive, Dublin, Ireland

3 Department of Research Engineering, University of Limerick, Limerick, Ireland 